\title{
ARTIFICIAL INTELLIGENCE APPLICATIONS IN SMART CITIES WASTE MANAGEMENT \& RECYCLING ${ }^{*}$
}

\section{İ. Haluk ÇERİBAŞI ${ }^{1}$, Görkem ÖZDENER ${ }^{2}$}

\author{
${ }^{\text {I} E N C O N ~ E n v i r o n m e n t a l ~ C o n s u l t a n c y ~ C o ., ~ A n k a r a, ~ T u r k e y, ~}$ \\ haluk@encon.com.tr, ORCID: 0000-0001-7878-8537 \\ ${ }^{2}$ Bahçeşehir University, Big Data Analytics and Management, Beşiktaş, Istanbul, \\ Turkey,gorkem.ozdener@bahcesehir.edu.tr,ORCID:0000-0002-3187-9359
}

\begin{abstract}
The rates of urbanization have been very rapid in the last 50 years and by 2050 about two-thirds of the world population will be living in cities. In the meantime, cities are becoming smart like everything else with the rapid development of technology. These developments are accompanied by environmental pressures on the urban infrastructure. Among these pressures, one of the most important ones is generation of wastes. Waste generation rates in urban environment/cities are increasing rapidly and use of technology in waste management, and especially recycling, has to be more closely considered. It is now possible to increase the rate of recycling and better waste management with applications of artificial intelligence (AI) and internet of things. In this article, AI applications in the field of waste management and recycling around the world will be discussed. The proposed model for this purpose applies an algorithm used for solving The Minimum Linear Arrangement Problem which is NP-hard. Some examples of applications used in the waste management sector are examined and conclusions, which could be useful for starting a new transformation about recycling and waste management, are reached.
\end{abstract}

Keywords: Waste, Waste Management, Recycling, Location Technology, Robotic, Smart City, Artificial Intelligence, Sustainability.

\footnotetext{
$1^{*}$ Received: 09.06.2021 - Accepted: 05.08.2021

DOI: 10.17932/EJEAS.2021.024/ejeas_v01i2002
} 


\section{INTRODUCTION}

In this research, artificial intelligence applications applied to waste management and recycling are examined. Any substance or object which the holder discards or intends/required to discard is called waste according to Article 3 of the EU Waste Framework Directive (2008/98/EC). According to this definition waste covers all refuse that could be recycled (referred as waste hereon) and could not be recycled (referred as garbage hereon). The residual material that remains after separating the materials such as paper, cardboard, glass, metal, plastic and which cannot be recycled is called as garbage, which is mostly decomposable food waste or yard waste. In this research, garbage is considered as something that needs to be disposed of, while waste is something that can be reused by separating the substances that make up waste.

Recycling aims to prevent unneeded use of resources and reducing the amount of waste to be disposed by sorting the waste at its source. Recycling and re-use of materials such as iron, steel, copper, lead, paper, plastic, rubber, glass, and electronic will block the depletion of natural resources. This approach will reduce the amount of foreign exchange paid for imported scrap material and save a great deal of energy used by many countries.

Recycling is also an important indicator that shows the development status of nations. While the population and expectations for everyday comforts on the planet are expanding, there is an inescapable expansion in utilization of resources and this puts pressure on our public/common assets (natural resources and environmental quality). Under these conditions, importance of the productive utilization of common assets turns out to be much more obvious. Zero waste policies/legislation and applications have been developed in line with these needs and are on the agenda of Turkey and the world.

\section{ARTIFICIAL INTELLIGENCE APPLICATIONS IN WASTE MANAGEMENT}

Today, a significant portion of the wastes generated in big cities can be recycled. Recycling and reuse methods that can reduce environmental problems also contribute to the national economies. With the increasing world population, the existence of techniques and models that help people separate recyclable wastes have become imperative for the efficient disposal of waste materials. At this point, Artificial Intelligence technology emerges. If the collection of unwanted materials/refuse is punctual, it enhances a resident's satisfaction. In this model heavy equipment is used by the collecting company's staff for collection of wastes. If waste collection service is satisfactory, residents promote it through the word of mouth [1].

When we examine the artificial intelligence applications that we can address in waste management and recycling, we will see different methods. There are different methods of predicting solid waste generation, which can be broadly classified into five main groups: descriptive statistical models, regression analysis, material flow method, time series analysis and artificial intelligence methods [2]. 
There are different studies carried out in different regions all over the world by different companies. One of these companies is ZenRobotics. They use robots to separate waste as a recycler/robotic sorting station and the flowchart and characteristics of this station can be seen in Figure 1. In this system, disorganized and mixed data creates a difficult environment for the robot to make predictions and to operate Therefore, specific arrangements have to be made with regard to homogenizing the waste flows. In addition, controls get harder due to external factors such as working environment temperature changes, dust and dirt, so controls on these are also needed.

Another robotic transforming company is AMP Robotics [3]. The working principles of their system can be summarized as follows. They create a database of millions of images. Then, neurons apply a deep learning algorithm to different product groups such as glass, plastic and metal according to their color, size and brand. Furthermore, the algorithm contextualizes the data in order to improve the classification of each material it collects. The collected data also provides transparency to recyclers so that they can optimize their operations and increase recycling rates.

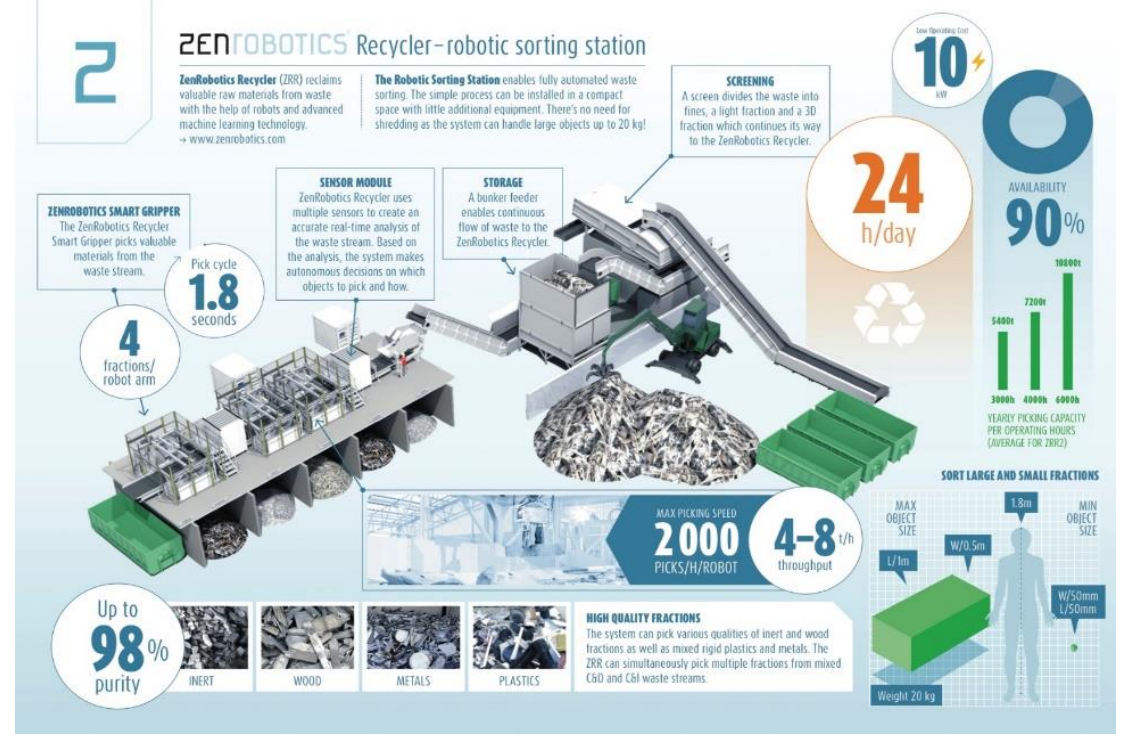

Figure 1: Robotic Sorting Station [4].

There are two basic approaches in using AI in waste management. The first one is the separation of wastes in different parts of the city at dumping places (trash bins). In this approach, waste is created by households, who dump their waste into a smart trash bin, where the smart trash bin collects waste by separating it. This method stands out with the fact that it reduces the cost and does not require an additional process. 
The second approach, on the other end of artificial intelligence applications of waste management, is collecting the garbage as a whole and to separate it by going through a process with the help of robotic automation. This method is more difficult to do and requires a high level of artificial intelligence software and engineering.

Currently, a fast development is being experienced in Smart Cities, where engineers, urban planners, architects and city managers are joining forces with the goal of boosting up the efficiency of municipal services and increasing benefits and convenience to their communities [5].

Engineering disciplines, municipal access networks, smart roads provide us some important information to improve the governance of cities. Information is transferred to the relevant units via wireless connections such as smart garbage bins or a prototype with sensor that measures the volume in containers. This data will be used to optimize waste collection and management strategies. AI sensors are a vital improvement over traditional optic option. They can identify the type of material and take into account special considerations. A manufacturer may buy a certain kind of recyclable plastic, for example, but only if it is clean from contaminants. AI sensors can separate out plastics used with chemicals from those that are clean, even if they're the same material [6].

\section{MAIN WASTE MANAGEMENT PROCESSES AND ARTIFICIAL INTELLIGENCE}

Waste management processes cover various steps starting from collection of waste and ending by final disposal. In this context, a stepwise summary of the process is provided in Table 1 below.

Table 1: Main Processes in Waste Management

\begin{tabular}{|c|l|c|}
\hline \multicolumn{3}{|c|}{ Waste Management and Recycling Steps } \\
\hline Steps & \multicolumn{1}{|c|}{ Details } & $\begin{array}{c}\text { Avg. } \\
\text { Time }\end{array}$ \\
\hline Collecting & $\begin{array}{l}\text { Separate collection of different types of wastes (e.g. plastic } \\
\text { wastes, metals, garbage, etc.) at the source is achieved using } \\
\text { various bins/cans such as indoor boxes, cages, containers } \\
\text { and piggy banks. }\end{array}$ & $\begin{array}{c}1-3 \\
\text { Days }\end{array}$ \\
\hline $\begin{array}{c}\text { Classificatio } \\
\text { n }\end{array}$ & $\begin{array}{l}\text { This process will allow classification of recyclable waste } \\
\text { materials collected separately at the source to be categorized } \\
\text { on the basis of glass, metal, plastic and paper. Waste } \\
\text { materials under this classification will be ideally delivered } \\
\text { to recycling facilities separately. }\end{array}$ & 1 Day \\
\hline
\end{tabular}




\begin{tabular}{|c|c|c|}
\hline Sorting & $\begin{array}{l}\text { The mixed recyclable wastes that arrived with collection } \\
\text { vehicles are separated in the separation band. They are } \\
\text { separated as paper, metal, glass and plastic wastes. Plastic } \\
\text { wastes can be divided into } 5 \text { different material types (PET, } \\
\text { PE, PP, PS, PVC) and transferred to the recycling industry. } \\
\text { Separated wastes form the raw materials for recycling. }\end{array}$ & $\begin{array}{c}6-12 \\
\text { Hours }\end{array}$ \\
\hline Pressing & $\begin{array}{l}\text { The classified and separated plastic wastes are then turned } \\
\text { into bales in the press machine so that they do not take up } \\
\text { more space in volume and sent to the storing area. }\end{array}$ & $\begin{array}{c}2-4 \\
\text { Hours }\end{array}$ \\
\hline Storing & $\begin{array}{l}\text { After the separation process, paper, plastic (including } \\
\text { pressed bales), metal and glass wastes are stored separately } \\
\text { in the stock area reserved for them and made ready for } \\
\text { transfer. They are sent to the recycling facility regularly by } \\
\text { the dedicated trucks. }\end{array}$ & $\begin{array}{l}2-3 \\
\text { Week } \\
\quad \mathrm{S}\end{array}$ \\
\hline
\end{tabular}

In the context of waste management, main discussion here will be on location-based technologies. In a nutshell, the proposed waste collection system is based on waste level data from trashcans in a metropolitan area. The data collected by sensors is sent over the Internet to a server where it is stored and processed [7].

The new trashcans, which are fully equipped by AI and some physical hardware, have some behavioral property. They have some sensors to determine the distance between top and bottom of the can. Thus, it sends information to server about how full it is. The optimization of these cycles is a combinatorial optimization problem. When the objective function of this optimization is to minimize the driving distance (equivalent to minimizing the length of the cycles), the problem is the same as the well known The Traveling Salesman Problem and closely related to the Minimum Linear Arrangement Problem, which are NP-hard [9]. The NP algorithm could be followed from Figure 2. 


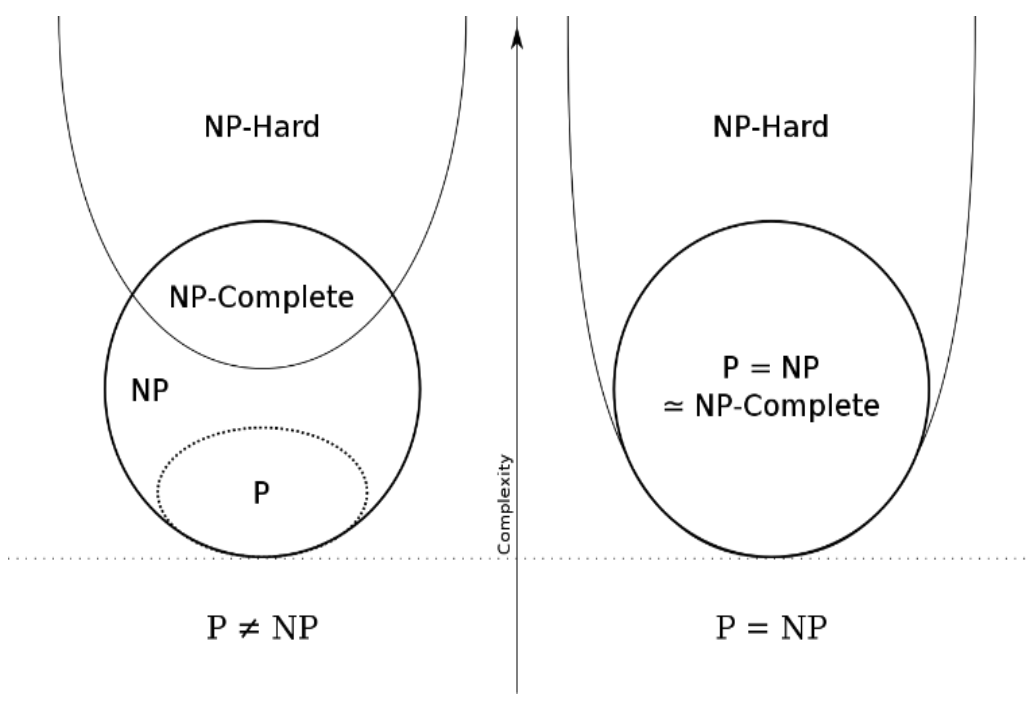

Figure 2: NP Algorithm Chart [10].

The main point in this part is using collected datasets for optimizing daily routines of trashcans collection. The key feature of this system is that it is designed to learn from experience and to make decisions not only on the daily waste level status, but also on future state forecast, traffic congestion, balanced cost-efficiency functions, and other affecting factors that cannot be foreseen without relevant data [8]. Due to the high number of route optimizations required to carry out the iterations, it was decided to use GA, which is relatively fast in providing near-optimal solutions. We understand that it is of great importance for the waste collection crews, who conduct this duty daily, use these technologies and optimize their work.

Last, but not least there are some Artificial Intelligence applications on waste management in Turkey as well. For example, Antalya Municipality uses smart containers. Sensors in these containers measure the filling rate of each container and instantly transfer the data to related person(s). This system also optimizes for unloading containers so that vehicles can use the shortest distance. Figure 3 shows an intelligent recycling terminal in China, which is a good example of use of AI in waste management and encouraging citizens for recycling. 


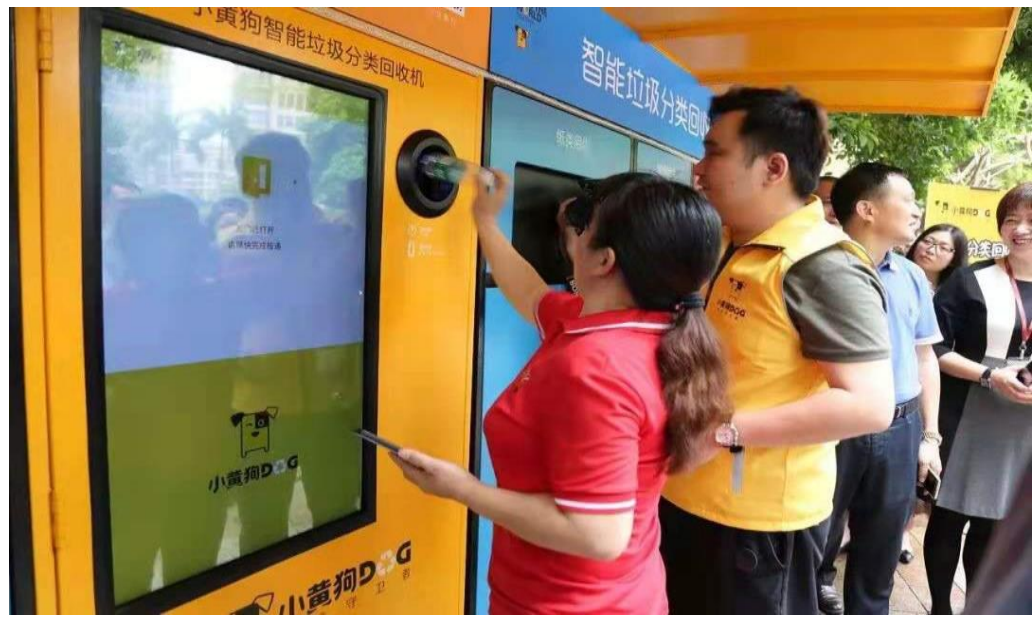

Figure 3: Intelligent Recycling Terminals [12].

Some of the best AI applications used for waste management and recycling in the world are summarized in Table 2 below.

Table 2: Best Applications about Waste Management and Recycling [13]

\begin{tabular}{|c|c|c|}
\hline \multicolumn{3}{|c|}{ Waste Management and Recycling Applications } \\
\hline Applications & Details & $\begin{array}{l}\text { Operati } \\
\text { ng } \\
\text { System }\end{array}$ \\
\hline IRecycle & $\begin{array}{l}\text { Earth } 911 \text {, which is an organization determined to } \\
\text { spread the word about the benefit of recycling waste, } \\
\text { launched the iRecycle App. The app helps users locate } \\
\text { the nearest recycle centers in their vicinity. Also, the app } \\
\text { teaches users the different do-it-yourself (DIY) ways to } \\
\text { recycle wastes. }\end{array}$ & $\begin{array}{c}\text { iOS \& } \\
\text { Android }\end{array}$ \\
\hline Gimme 5 & $\begin{array}{l}\text { There are different types of plastics; some are not } \\
\text { recyclable, while some are known to be more profitable } \\
\text { when recycled. The plastic type that falls under the latter } \\
\text { category is the number } 5 \text { plastic which is polypropylene. } \\
\text { Gimme } 5 \text { is an app that helps users to identify the right } \\
\text { recyclable plastics. }\end{array}$ & $\mathrm{iOS}$ \\
\hline $\begin{array}{l}\text { Waste } \\
\text { Management } \\
\text { App }\end{array}$ & $\begin{array}{l}\text { The Waste Management App is one of the most } \\
\text { comprehensive apps for managing waste. It functions as } \\
\text { a waste payment app as well as a hub to access local } \\
\text { information and policies on waste management. In }\end{array}$ & $\mathrm{iOS}$ \\
\hline
\end{tabular}




\begin{tabular}{|c|l|c|}
\hline & $\begin{array}{l}\text { addition, users can use this app to monitor and track } \\
\text { waste pickups. }\end{array}$ & \\
\hline $\begin{array}{c}\text { RecycleNatio } \\
\mathbf{n}\end{array}$ & $\begin{array}{l}\text { RecycleNation is a mobile app that helps improve } \\
\text { recycling rates in the US. Also, the app helps users } \\
\text { locate recycling centers on the map as well as their } \\
\text { contact information. Furthermore, RecycleNation } \\
\text { comes with a news portal that provides users with } \\
\text { environmental trends and news. }\end{array}$ & iOS \\
\hline My Waste & $\begin{array}{l}\text { The My Waste mobile app partners with municipalities } \\
\text { all over the world to provide its users up-to-date waste } \\
\text { management and recycling news, policies and } \\
\text { information. Another feature of the app is the waste } \\
\text { collection and recycling dates reminder. }\end{array}$ & iOS \& \\
\hline
\end{tabular}

With the introduction of artificial intelligence applications at every point of our lives, we are stepping into a more livable world by saving money, time and energy on this and other similar practices. Continuity is a solid part of an operation in working up any process. Whatever is done well today can be done better tomorrow. In these environments, collaborative robots equipped with artificial intelligence make purposeful contributions to process improvement from the day they start functioning. With artificial intelligencebased systems that can be integrated into co-conspirator robots, robotic systems do much more than machines for nasty, boring and hazardous jobs.

\section{CONCLUSION}

With the rapid development in technology, many innovations are applied in our daily life. While some of these developments do not contribute directly to sustainability of natural resources and development, some of them show great importance for human welfare and sustainable development. Artificial intelligence applications in the field of waste management and recycling are among the technological developments that serve for environmental sustainability and human welfare in the long run.

The problems related to climate change/global warming and degradation of environmental quality are mainly due to rapid population increase and associated need for economic growth without giving necessary attention to environmental issues. In this context, use of technology was also focused solely on economic development and missed the need for conservation of natural resources and ecosystem. However, with the new millennium more strict policies and targets were put down by nations and international organizations to stop environmental degradation and to achieve better environmental conditions. In addition, awareness of the public has been exponentially increasing through 
improved communication technology and municipalities are acting more responsibly concerned with environmental impacts of wastes.

In this regard, AI technologies are being more broadly used especially in developed countries in the field of environmental and specifically waste management. In the management of solid wastes recycling, reuse and recovery are becoming more and more important and technological developments are supporting better application of these techniques. Thus, improvement of AI applications in this field and their more widely use (with decreasing of associated costs) would significantly contribute to environmental protection and would be key factors in sustainable development.

\section{REFERENCES}

[1] Zeithaml, V.A., 2000. Service quality, profitability, and the economic worth of customers: what we know and what we need to learn. J. Acad. Mark. Sci. 28, 67-85.

[2] Abbasi M, El Hanandeh A (2016) Forecasting municipal solid waste generation using artificial intelligence modeling approaches. Waste Management 56:13-22.

[3] https://zenrobotics.com/, Online, Web Page

[4] https://wastelessfuture.com/revolutionizing-recycling-pick-by-pick/

[5] Kunzmann K.R., Smart Cities: A New Paradigm of Urban Development. Crios, pp. 9-20, 1/2014. doi: 10.7373/77140

[6] https://datafloq.com/read/how-ai-is-assisting-with-wastemanagement/7305\#: :text=AI\%20sensors $\% 20$ are $\% 20 \mathrm{a} \% 20$ vital,only $\% 20 \mathrm{it}$ 's $\% 20 \mathrm{cl}$ ean $\% 20$ from $\% 20$ contaminants.

[7] Jose M. Gutierrez, Smart Waste Collection System Based on Location Intelligence, Conference Organized by Missouri University Science and Technology 2015-San Jose, CA. Procedia Computer Science 61 (2015) 120-127

[8] Michael Jensen, Smart Waste Collection System Based on Location Intelligence, Conference Organized by Missouri University Science and Technology 2015-San Jose, CA. Procedia Computer Science 61 (2015) 120-127

[9] Petit, J., Experiments on the minimum linear arrangement problem, Systems Informatics, 2001, vol. 8, pp. 112-128, 2001.

[10] https://commons.wikimedia.org/wiki/File:P_np_np-complete_np-hard.svg

[11] Achillas, C., Aidonis, D., Vlachokostas, C., Moussiopoulos, N., Banias, G., Triantafillou, D., 2012. A multi-objective decision-making model to select waste electrical and electronic equipment transportation media. Resour. Conserv. Recycl. 66

[12] http://shekoudaily.com/blog/smart-recycling-machines-in-nanshan-offer-moneyback.html

[13] https://medium.com/@swachhcoin/top-5-innovative-and-informative-wastemanagement-and-recycling-apps-b93f103c3e7e 